\title{
Poly(4-vinylpyridinium butane sulfonic acid) hydrogen sulfate: An efficient, heterogeneous poly(ionic liquid), solid acid catalyst for the one-pot preparation of 1-amidoalkyl-2-naphthols and substituted quinolines under solvent-free conditions
}

\author{
Ali Reza Kiasat*, Arash Mouradzadegun, Seyyed Jafar Saghanezhad \\ Chemistry Department, College of Science, Shahid Chamran University, P. O. Box 61357-4-3169, Ahvaz, Iran
}

\section{A R T I C L E I N F O}

\section{Article history:}

Received 6 June 2013

Accepted 10 July 2013

Published 20 October 2013

Keywords:

Solvent-free

$\beta$-Naphthol

Poly(ionic liquid)

Acetamide

Quinoline

2-Aminobenzophenone

\begin{abstract}
A B S T R A C T
Poly(4-vinylpyridinium butane sulfonic acid) hydrogen sulfate has been used as an efficient dual acidic catalyst for the one-pot preparation of 1-amidoalkyl-2-naphthols and substituted quinolines under solvent-free conditions. The catalyst was characterized by Fourier transform infrared spectroscopy, scanning electron microscopy, and thermo-gravimetric analysis. The results revealed several advantages to our new catalyst system, including its reusability, facile work-up procedure, eco-friendly reaction conditions, short reaction time, and high product yields.
\end{abstract}

(C) 2013, Dalian Institute of Chemical Physics, Chinese Academy of Sciences. Published by Elsevier B.V. All rights reserved.

\section{Introduction}

Poly(ionic liquid)s (PILs) have emerged as new materials with a wide variety of potential application in a number of different fields, including energy and environmental research, analytical chemistry, materials science, biotechnology, surface science, and catalyst development [1]. There are several advantages associated with the use of PILs over ionic liquids (ILs), including enhanced mechanical stability, improved processability, durability, and spatial controllability. Two basic strategies have been reported for the synthesis of PILs, including (1) the direct polymerization of IL monomers, and (2) the chemical modification of existing polymers [2].

Organic reactions conducted under solvent-free conditions have attracted considerable levels of attention from research- ers throughout the world, most notably from the perspective of green chemistry [3]. The synergic effect of performing condensation reactions under solvent-free conditions with a heterogeneous catalyst could enhance their efficiency from an economic as well as an ecological point of view $[4,5]$. The application of such as eco-friendly, solvent-free approach effectively opens up numerous possibilities for conducting rapid organic syntheses and functional group transformations more efficiently [6].

1-Amidoalkyl-2-naphthol derivatives have been identified as compounds of considerable interest because they possess a broad range of biological, medicinal, and pharmacological activity [7-13]. Given the importance of these compounds, considerable research efforts have been devoted to the development of multi-component reactions (MCRs) for the synthesis of

\footnotetext{
*Corresponding author. Tel/Fax: +98-611-3331746; E-mail: akiasat@scu.ac.ir This work was supported by Shahid Chamran University. 
1-amidoalkyl-2-naphthols from aldehydes, $\beta$-naphthols, and amides under a range of different reaction conditions using a variety of different catalysts, including montmorillonite $\mathrm{K} 10$ [14], iodine [15], $\mathrm{Fe}\left(\mathrm{HSO}_{4}\right)_{3}$ [16], $\mathrm{K}_{5} \mathrm{CoW}_{12} \mathrm{O}_{40} \cdot 3 \mathrm{H}_{2} \mathrm{O}$ [17], sulfamic acid [18], and thiamine hydrochloride [19].

Of the many different methodologies reported for the preparation of quinolines, the Friedländer reaction is still one of the most straightforward protocols, and this reaction has recently been reviewed in some detail [20]. The Friedländer synthesis involves a condensation reaction followed by a cyclodehydration reaction between an aromatic 2-aminoaldehyde or ketone and an aldehyde or ketone possessing an $\alpha$-activated methylene group [21]. Although various catalysts have been proposed for the Friedländer annulation reaction, acidic catalysts have been shown to be superior to basic catalysts for this transformation [22]. As well as acidic catalysts such as Brönsted acids [23-27] and Lewis acids [28-30], ionic liquids [31] and a range of catalysts [32,33] have also been reported to promote this reaction.

In a continuation of our efforts towards the synthesis of new solid acid catalysts and their subsequent application in organic synthesis [34,35], we recently synthesized poly(4-vinylpyridinium butane sulfonic acid) hydrogen sulfate, P(4VPBSA)$\mathrm{HSO}_{4}$, as a novel dual acidic PIL heterogeneous catalyst for the one-pot preparation of 1,8-dioxo-octahydro-xanthenes under solvent-free conditions [36]. To further expand upon the potential applications of this catalyst, herein we describe our most recent work towards exploring the catalytic activity of this catalyst in the one-pot preparation of amidoalkyl naphthols (Scheme 1) and substituted quinolines (Scheme 2) under solvent-free conditions.

\section{Experimental}

\subsection{General}

All of the commercially available chemicals were purchased from Fluka and Merck and used without further purification. Poly(4-vinyl pyridine) cross-linked with 2\% DVB (100-200 mesh, MW: 60000) was purchased from Fluka. All of the products were characterized for their physical properties and by comparison with authentic samples. The reactions were moni- tored by TLC on silica gel polygram SILG/UV 254 plates. Infrared (IR) spectra were recorded on a BOMEM MB-Series 1998 Fourier transform infrared spectrophotometer as $\mathrm{KBr}$ pellets in the range of $4000-400 \mathrm{~cm}^{-1} .{ }^{1} \mathrm{H}$ and ${ }^{13} \mathrm{C}$ NMR spectra were recorded in $\mathrm{CDCl}_{3}$ or DMSO- $d_{6}$ on a Bruker Advanced DPX 400 $\mathrm{MHz}$ spectrometer using TMS as an internal reference. The thermal stability of the supported catalyst was examined using a BÄHR SPA 503 thermo-gravimetric analyzer at a heating rate of $10^{\circ} \mathrm{C} / \mathrm{min}$ over a temperature range of $40-950{ }^{\circ} \mathrm{C}$. Scanning electron microscopy analyses were carried out using a LEO 1455VP scanning electron microscope, operating at 1-30 kV. Elemental analyses were conducted on an ECS 4010 Costech elemental combustion system.

\subsection{General procedure for the preparation of the catalyst}

1,4-Butane sultone ( $2.72 \mathrm{~g}, 20 \mathrm{mmol}$ ) was slowly added to a dispersion of poly(4-vinylpyridine) (2.1 g) in toluene at ambient temperature, and the resulting mixture was stirred for $2 \mathrm{~h}$. The temperature was then raised to $70{ }^{\circ} \mathrm{C}$ and the mixture was stirred for $24 \mathrm{~h}$. The mixture was then cooled to ambient temperature and the resulting solid was filtered. The filter-cake was then washed sequentially with dichloromethane and methanol before being dried under vacuum at $55^{\circ} \mathrm{C}$. The dried white solid ( $3.1 \mathrm{~g}$ ) was dispersed in $15 \mathrm{~mL}$ of $\mathrm{H}_{2} \mathrm{O}$ in a $50 \mathrm{~mL}$ round bottom flask, and excess sulfuric acid was then added into the flask in a drop-wise manner at ambient temperature. Upon completion of the addition, the mixture was stirred for 12 $\mathrm{h}$ at ambient temperature. The resulting cream-colored solid was washed several times with deionized water before being dried under vacuum at $55{ }^{\circ} \mathrm{C}$ for $24 \mathrm{~h}$. Subsequent elemental analysis of the catalyst revealed that the CHNS percentages were as follows: N 6.83\%, C 48.47\%, H 6.11\%, and S 12.74\%.

\subsection{Determination of the acidity of the catalyst}

To determine the acidity of the catalyst, $\mathrm{P}(4 \mathrm{VPBSA}) \mathrm{HSO}_{4}(20$ $\mathrm{mg}$ ) was added to a $25 \mathrm{~mL}$ aqueous solution of $\mathrm{NaCl}(1 \mathrm{~mol} / \mathrm{L}$, $\mathrm{pH}=6.64$ ), and the resulting mixture was stirred for $2 \mathrm{~h}$. The $\mathrm{pH}$ of the solution was reduced to 2.81 , indicating the presence of $1.94 \mathrm{mmol} / \mathrm{g}$ of $\mathrm{H}^{+}$.

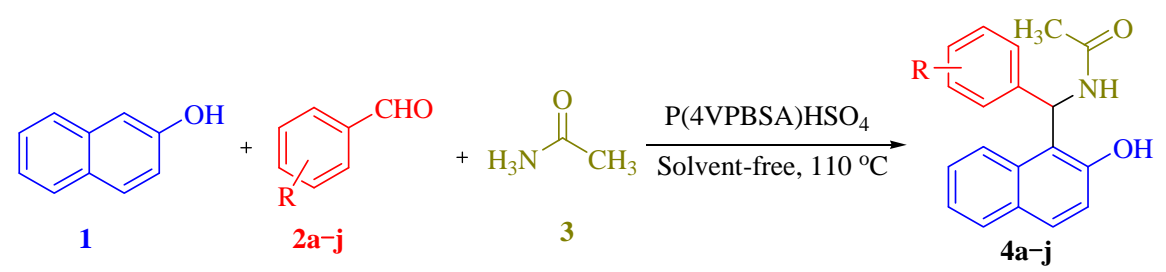

Scheme 1. One-pot preparation of amidoalkyl naphthols.<smiles>[R]C(=O)c1cc([X])ccc1N</smiles>

5a: $\mathrm{X}=\mathrm{H}, \mathrm{R}=\mathrm{Ph}$ 5b: $\mathrm{X}=\mathrm{Cl}, \mathrm{R}=\mathrm{Ph}$<smiles>[R]CC([R])=O</smiles>

6a-j

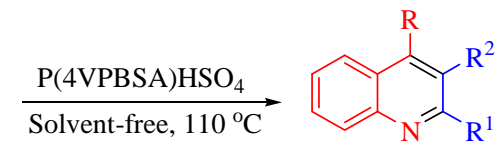

$7 \mathbf{a}-\mathbf{j}$

Scheme 2. One-pot preparation of substituted quinolones. 
2.4. Typical procedure for the preparation of the 1-amidoalkyl-2-naphthols

A mixture of aromatic aldehyde (1.0 mmol), $\beta$-naphthol $(1.0$ mmol), acetamide (1.2 mmol), and P(4VPBSA)HSO 4 (0.05 g, 10 mol\%) was stirred for 10-20 min under solvent-free conditions at $110{ }^{\circ} \mathrm{C}$. Upon completion of the reaction by TLC (ethyl acetate $/ n$-hexane $(2: 5, \mathrm{v} / \mathrm{v})$ eluent), the insoluble crude product was dissolved in hot ethanol and the $\mathrm{P}(4 \mathrm{VPBSA}) \mathrm{HSO}_{4}$ was removed by filtration. The desired product subsequently precipitated from the filtrate on cooling and was collected by filtration in high purity. Further purification could be achieved as necessary by recrystallization of this material from aqueous ethanol.

\subsection{Typical procedure for the preparation of substituted quinolines}

A mixture of 2-aminobenzophenone (1 mmol), acetylacetone (1.0 mmol), and $\mathrm{P}(4 \mathrm{VPBSA}) \mathrm{HSO}_{4}(0.05 \mathrm{~g}, 10 \mathrm{~mol} \%)$ was stirred for 30-60 min under solvent-free conditions at 110 ${ }^{\circ} \mathrm{C}$. Upon completion of the reaction by TLC (ethyl acetate $/ n$-hexane $(2: 5, v / v))$, the insoluble crude product was dissolved in hot ethanol and the $\mathrm{P}(4 \mathrm{VPBSA}) \mathrm{HSO}_{4}$ was removed by filtration. The desired product subsequently precipitated from the filtrate on cooling and was collected by filtration in high purity. Further purification could be achieved as necessary by recrystallization of this material from ethanol.

\subsection{Selected spectra of some representative compounds}

$N$-[(3-nitro phenyl)-(2-hydroxy-naphthalen-1-yl)-methyl]acetamide (Table 2, Entry 3, 4c). IR (KBr, $\mathrm{cm}^{-1}$ ): 3403, 3141, 3058, 2977, 1641, 1527, 1437, 1348, 1280, 1071, 990, 832, 745; ${ }^{1} \mathrm{H}$ NMR (400 MHz, DMSO- $d_{6}$ ): $\delta 2.01(\mathrm{~s}, 3 \mathrm{H}), 7.17(\mathrm{t}, J=8.0$ $\mathrm{Hz}, 1 \mathrm{H}$ ), 7.19 (d, $J=8.6 \mathrm{~Hz}, 1 \mathrm{H}), 7.24(\mathrm{t}, J=7.4 \mathrm{~Hz}, 1 \mathrm{H}), 7.38$ (t, $J$ $=7.4 \mathrm{~Hz}, 1 \mathrm{H}), 7.51(\mathrm{~m}, 2 \mathrm{H}), 7.78(\mathrm{t}, J=8.6 \mathrm{~Hz}, 2 \mathrm{H}), 7.83(\mathrm{br}, 1 \mathrm{H})$, 7.97-7.99 (m, 2H), 8.58 (d, $J=8.0 \mathrm{~Hz}, 1 \mathrm{H}), 10.16(\mathrm{~s}, 1 \mathrm{H}) ;{ }^{13} \mathrm{C}$ NMR (100 MHz, DMSO- $d_{6}$ ): $\delta$ 23.1, 48.2, 118.3, 118.9, 120.9, $121.8,123.1,127.3,123.2,128.9,129.2,130.1,130.5,132.7$, $133.4,145.9,148.2,153.9,170.3$.

$\mathrm{N}$-[(2-Chloro phenyl)-(2-hydroxy naphthalen-1-yl)-methyl]acetamide (Table 2, Entry 7, 4g). IR (KBr, cm-1): 3418, 3064, $1655,1580,1534,1509,1470,1437,1369,1334,1270,1062$, 1036, 815, 752, 569; ${ }^{1} \mathrm{H}$ NMR (400 MHz, DMSO-d $\left.d_{6}\right): \delta 1.91(\mathrm{~s}$, $3 \mathrm{H}), 7.56-7.08(\mathrm{~m}, 8 \mathrm{H}), 7.73(\mathrm{~d}, J=7.6 \mathrm{~Hz}, 1 \mathrm{H}), 7.78(\mathrm{~d}, J=6.1$
$\mathrm{Hz}, 1 \mathrm{H}$ ), 8.00 (d, J = 7.0 Hz, 1H), 8.50 (s, 1H), 9.75 (s, 1H); ${ }^{13} \mathrm{C}$ NMR (100 MHz, DMSO- $\left.d_{6}\right): \delta 22.3,47.5,117.0,118.5,122.1$, 122.7, 126.1, 126.2, 127.9, 128.2, 128.4, 129.1, 129.2, 129.7, $132.1,132.7,139.7,153.5,168.4$.

3,3-Dimethyl-9-phenyl-3,4-dihydroacridin-1(2H)-one (Table 3, Entry 5, 7e). IR ( $\left.\mathrm{KBr}, \mathrm{cm}^{-1}\right)$ : 3077, 2954, 2866, 1697, 1555, 1477, 1384; ${ }^{1} \mathrm{H}$ NMR $\left(\mathrm{CDCl}_{3}, 400 \mathrm{MHz}\right): \delta 1.16(\mathrm{~s}, 6 \mathrm{H})$, $2.56(\mathrm{~s}, 2 \mathrm{H}), 3.27(\mathrm{~s}, 2 \mathrm{H}), 7.17(\mathrm{~d}, 2 \mathrm{H}, J=6.5 \mathrm{~Hz}), 7.40(\mathrm{t}, 1 \mathrm{H}, J=$ $7.5 \mathrm{~Hz}), 7.47-7.50(\mathrm{~m}, 4 \mathrm{H}), 7.75(\mathrm{t}, 1 \mathrm{H}, J=7.0 \mathrm{~Hz}), 8.06(\mathrm{~d}, 1 \mathrm{H}, J$ $=8.5 \mathrm{~Hz}) ;{ }^{13} \mathrm{C}$ NMR $\left(100 \mathrm{MHz}\right.$, DMSO $\left.d_{6}\right): \delta 28.3,32.8,47.8,53.8$, 126.0, 127.1, 127.7, 127.9, 128.3, 128.6, 128.7, 128.9, 131.3, 132.1, 134.6, 137.8, 148.7, 150.1, 161.6, 197.7.

Ethyl 6-chloro-2-methyl-4-phenylquinoline-3-carboxylate (Table 3, Entry 7, 7g). IR (KBr, cm-1): 3064, 2983, 1725, 1605, 1224, 907, 732; ${ }^{1} \mathrm{H}$ NMR (400 MHz, $\left.\mathrm{CDCl}_{3}\right): \delta 0.92-0.95(\mathrm{t}, 3 \mathrm{H}, J$ $=7.08 \mathrm{~Hz}), 2.73(\mathrm{~s}, 3 \mathrm{H}), 4.03-4.07(\mathrm{q}, 2 \mathrm{H}, J=7.08 \mathrm{~Hz})$, 7.32-8.00 (m, 8H); ${ }^{13} \mathrm{C}$ NMR (100 MHz, DMSO $\left.d_{6}\right): \delta 13.8,23.7$, 61.6, 124.9, 125.7, 129.1, 129.3, 129.4, 129.5, 131.3, 131.4, $131.8,134.6,145.1,145.9,155.0,167.5$.

\section{Results and discussion}

The $\mathrm{P}(4-\mathrm{VPBSA}) \mathrm{HSO}_{4}$ catalyst was readily prepared in two steps via the reaction of $\mathrm{P}(4 \mathrm{VP})$ with 1,4-butane sultone followed by acidification of the resulting product with sulfuric acid (Scheme 3).

FT-IR spectroscopy was employed to confirm the successful functionalization of the $\mathrm{P}(4 \mathrm{VP})$ with 1,4-butane sultone and its subsequent acidification with sulfuric acid. The FT-IR spectrum of $\mathrm{P}(4 \mathrm{VPBSA}) \mathrm{HSO}_{4}$ is shown in Fig. 1. The spectrum contained

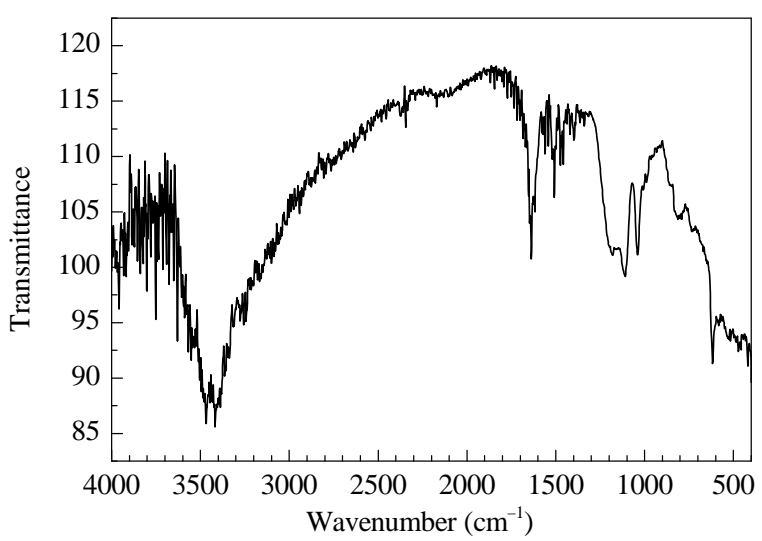

Fig. 1. FT-IR spectrum of $\mathrm{P}(4 \mathrm{VPBSA}) \mathrm{HSO}_{4}$.<smiles>CC(C)(C)CC(CCCC(CC(C)(C)C)c1ccncc1)c1ccncc1</smiles><smiles>O=S1(=O)CCCOS1</smiles><smiles>CC(C)(C)CC/C=C/C=NCCCCS(=O)(=O)[O-]</smiles><smiles>CCCCC(c1cc[n+](CCCCS)cc1)C(C)(C)C</smiles><smiles>[R5]SCCCCCCC</smiles><smiles></smiles>

Scheme 3. Preparation of the P(4-VPBSA) catalyst. 


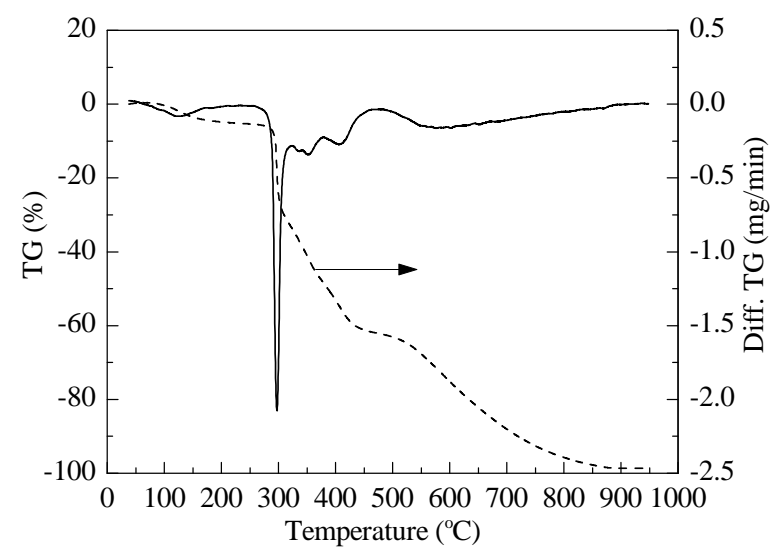

Fig. 2. TGA curves of $\mathrm{P}(4 \mathrm{VPBSA}) \mathrm{HSO}_{4}$.

peaks at 1039,1113 , and $1187 \mathrm{~cm}^{-1}$ corresponding to $\mathrm{S}=0$ stretching vibrations of the $-\mathrm{SO}_{3} \mathrm{H}$ groups, as well as a broad peak around $3400 \mathrm{~cm}^{-1}$ corresponding to the $\mathrm{OH}$ vibration.

The TGA results (Fig. 2) revealed that the catalyst was completely stable below $300{ }^{\circ} \mathrm{C}$ and could therefore be applied without any danger of degradation.

Analysis of the catalyst by SEM allowed for the morphology of the catalyst particles to be studied. The SEM micrograph of a sample of the $\mathrm{P}(4 \mathrm{VP})$ revealed that this material was formed through the agglomeration of grains with smooth surface. The SEM micrograph of the acidic catalyst, $\mathrm{P}(4 \mathrm{VPBSA}) \mathrm{HSO}_{4}$, showed that the primary smoothness had changed, as a consequence of the chemical modifications, to a coarse surface (Fig 3 ). It is noteworthy that the dispersion of the catalyst increased following the functionalization of the $\mathrm{P}(4 \mathrm{VP})$.

Following the qualification of the catalyst, it was decided to evaluate the catalytic activity of the catalyst for the preparation of 1-amidoalkyl-2-naphthols. The reaction of benzaldehyde (1.0 mmol) with $\beta$-naphthol (1.0 mmol) and acetamide (1-1.5 mmol) was selected as a model reaction, and the reaction was evaluated using different loadings of the $\mathrm{P}\left(4 \mathrm{VPBSA} \mathrm{HSO}_{4}\right.$ (i.e., 5,10 , and $15 \mathrm{~mol} \%$ ) under solvent-free conditions at $110{ }^{\circ} \mathrm{C}$ (Table 1). The results revealed that a catalyst loading of 10 mol\% with $1.2 \mathrm{mmol}$ of acetamide at $110{ }^{\circ} \mathrm{C}$ gave the highest yield with the shortest reaction time. Then use of a higher loading of the catalyst (15 mol\%) did not have a discernible impact on the yield or the rate of the reaction (Table 1).

With the optimal reaction conditions in hand, consisting of a 1:1:1.2 molar ratios of aldehyde, $\beta$-naphthol and acetamide with a $10 \mathrm{~mol} \%$ loading of $\mathrm{P}(4 \mathrm{VPBSA}) \mathrm{HSO}_{4}$ at $110{ }^{\circ} \mathrm{C}$ under
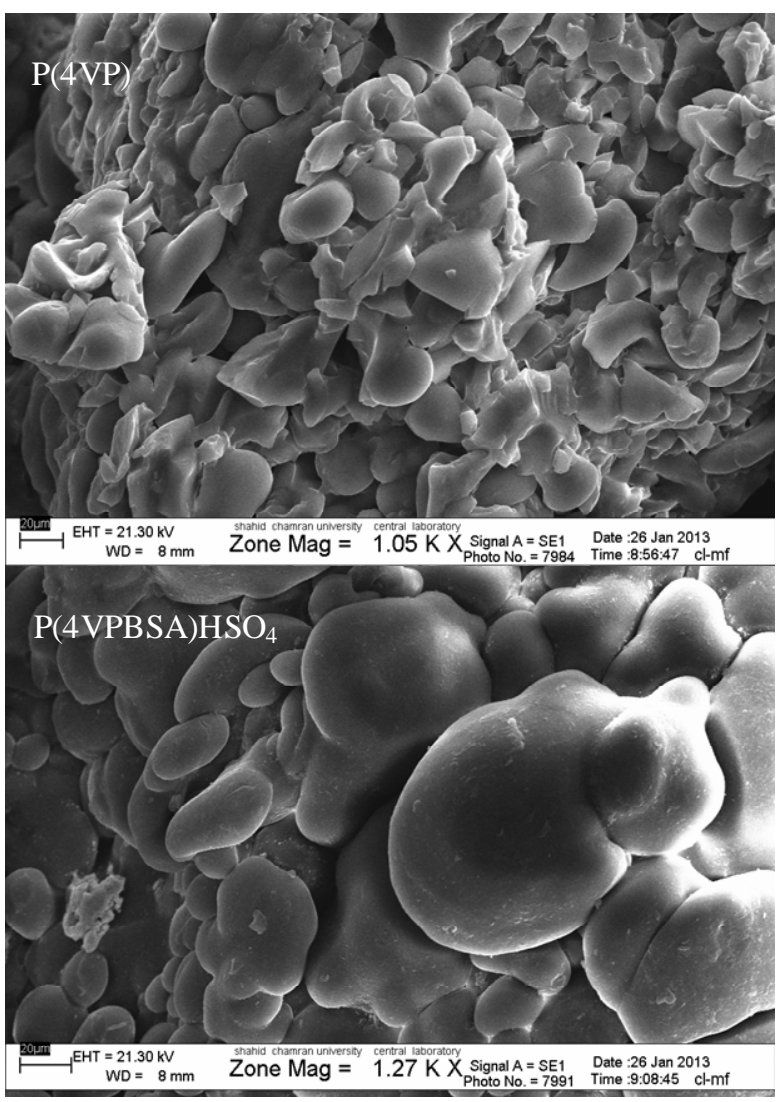

Fig. 3. SEM images of $\mathrm{P}(4 \mathrm{VP})$ and $\mathrm{P}(4 \mathrm{VPBSA}) \mathrm{HSO}_{4}$

solvent-free conditions, the generality and synthetic scope of this coupling protocol were demonstrated through the synthesis of a series of 1-amidoalkyl-2-naphthols (Table 2). Pleasingly, a wide range of aromatic aldehydes with electron donating or electron withdrawing groups was well tolerated under the optimized reaction conditions. Although the reaction time remained largely unchanged, we postulated that the electron withdrawing groups accelerated the reaction on the basis of the enhanced electrophilicity of the $\beta$-carbon, which facilitates the subsequent Michael addition. It is also noteworthy that aromatic aldehydes bearing electron withdrawing groups provided higher yields of the products. The time taken for complete conversion (monitored by TLC) as well as the isolated yields are recorded in Table 2. All of the compounds were characterized by IR, and ${ }^{1} \mathrm{H}$ and ${ }^{13} \mathrm{C}$ NMR, and their spectra were compared with those of the authentic samples.

We then proceeded to evaluate the catalytic activity of the

Table 1

Optimum conditions for the reaction of $\beta$-naphthol ( $1 \mathrm{mmol})$, with benzaldehyde $(1 \mathrm{mmol})$, and acetamide $(1-1.5 \mathrm{mmol})$ with different loadings of the $\mathrm{P}(4 \mathrm{VPBSA}) \mathrm{HSO}_{4}$ catalyst.

\begin{tabular}{|c|c|c|c|c|c|}
\hline Entry & Acetamide (mmol) & Catalyst (mol\%) & $\mathrm{T} /{ }^{\circ} \mathrm{C}$ & Time (min) & Yield (\%) \\
\hline 1 & 1.0 & - & 80 & 120 & 20 \\
\hline 2 & 1.0 & 5 & 80 & 120 & 45 \\
\hline 3 & 1.1 & 5 & 100 & 120 & 58 \\
\hline 4 & 1.2 & 5 & 110 & 80 & 65 \\
\hline 5 & 1.0 & 10 & 80 & 60 & 72 \\
\hline 6 & 1.2 & 10 & 110 & 12 & 95 \\
\hline 7 & 1.2 & 15 & 100 & 15 & 90 \\
\hline 8 & 1.5 & 15 & 110 & 10 & 89 \\
\hline
\end{tabular}


Table 2

One-pot preparation of 1-amidoalkyl-2-naphthols promoted by $\mathrm{P}(4 \mathrm{VPBSA}) \mathrm{HSO}_{4}$ under solvent-free conditions at $110^{\circ} \mathrm{C}$

\begin{tabular}{|c|c|c|c|c|c|c|}
\hline \multirow{2}{*}{ Entry } & \multirow{2}{*}{$\mathrm{R}$} & \multirow{2}{*}{ Product } & \multirow{2}{*}{ Time (min) } & \multirow{2}{*}{ Yield (\%) } & \multicolumn{2}{|c|}{ Melting point $\left({ }^{\circ} \mathrm{C}\right)$} \\
\hline & & & & & Found & Ref. \\
\hline 1 & $\mathrm{H}$ & & 12 & 95 & $242-243$ & $245-246$ [16] \\
\hline 2 & $4-\mathrm{NO}_{2}$ & & 10 & 98 & $245-246$ & $248-250$ [16] \\
\hline 3 & $3-\mathrm{NO}_{2}$ & & 10 & 92 & $243-245$ & $241-242$ [16] \\
\hline 4 & $3-\mathrm{F}$ & & 20 & 90 & $249-250$ & $248-249$ [16] \\
\hline 5 & $4-\mathrm{CH}_{3}$ & & 15 & 91 & $220-221$ & $222-223$ [16] \\
\hline 6 & 4-OMe & & 15 & 89 & $184-186$ & $183-185$ [16] \\
\hline 7 & $2-\mathrm{Cl}$ & & 15 & 96 & $210-211$ & $213-215$ [16] \\
\hline 8 & $4-\mathrm{CN}$ & & 10 & 97 & $255-257$ & $260-262$ [37] \\
\hline 9 & $4-\mathrm{OH}$ & & 15 & 92 & $212-214$ & $207[38]$ \\
\hline 10 & 4-Cl & & 10 & 93 & $224-226$ & $223-225$ [16] \\
\hline
\end{tabular}

catalyst in the preparation of substituted quinolines. Following the optimization of the reaction conditions (i.e., 2-aminobenzophenone (1.0 mmol) and acetylacetone ( $1.2 \mathrm{mmol})$ with a 10 mol\% loading of $\left.\mathrm{P}(4 \mathrm{VPBSA}) \mathrm{HSO}_{4}\right)$, a series of substituted quinolines were prepared at $110{ }^{\circ} \mathrm{C}$ under solvent-free conditions (Table 3).
Given the increasing levels of interest in green chemistry, we decided to evaluate the recyclability and reusability of the catalyst. Upon completion of the reaction, the separated catalyst was washed with hot ethanol and dried. The catalyst was then used for four more cycles. Pleasingly, the catalyst gave a consistent performance across all four cycles (Fig. 4). 
Table 3

One-pot preparation of substituted quinolines via the reaction of an aminoketone (1.0 mmol) with an $\alpha$ - $\mathrm{CH}$ acidic ketone (1.2 mmol) in the presence of the $\mathrm{P}(4 \mathrm{VPBSA}) \mathrm{HSO}_{4}$ catalyst under solvent-free conditions at $110^{\circ} \mathrm{C}$.

\begin{tabular}{|c|c|c|c|c|c|c|c|}
\hline \multirow{2}{*}{ Entry } & \multirow{2}{*}{ Aminoketone } & \multirow{2}{*}{ Ketone } & \multirow{2}{*}{ Product } & \multirow{2}{*}{$\begin{array}{l}\text { Time } \\
(\mathrm{min})\end{array}$} & \multirow{2}{*}{$\begin{array}{c}\text { Yield } \\
(\%)\end{array}$} & \multicolumn{2}{|c|}{ Melting point $\left({ }^{\circ} \mathrm{C}\right)$} \\
\hline & & & & & & Found & Ref. \\
\hline 1 & $5 a$ & $\mathbf{b a}$ & $7 \mathbf{a}$ & 45 & 88 & 114 & $112-115$ [27] \\
\hline 2 & $5 \mathbf{a}$ & EtO & $\mathrm{Ph} \quad \mathrm{O}$ & 50 & 90 & 95 & 93 [27] \\
\hline 3 & $5 a$ & 6c & 7c & 60 & 75 & 142 & 138-141 [27] \\
\hline 4 & $5 a$ & & & 40 & 92 & 152 & $151-153$ [27] \\
\hline 5 & $5 a$ & & & 30 & 95 & 190 & 192 [39] \\
\hline 6 & & & & 40 & 91 & 152 & $151[31]$ \\
\hline 7 & $5 b$ & EtO & & 45 & 92 & 110 & 108 [31] \\
\hline 8 & $5 b$ & & & 50 & 78 & 165 & $163[31]$ \\
\hline 9 & $5 b$ & & & 35 & 80 & 186 & $187-188$ [39] \\
\hline 10 & $5 \mathbf{b}$ & & & 30 & 93 & 210 & 211 [39] \\
\hline
\end{tabular}

To demonstrate the superiority of $\mathrm{P}(4 \mathrm{VPBSA}) \mathrm{HSO}_{4}$ over the other catalysts reported in the literature for the same reaction, the reaction of benzaldehyde with $\beta$-naphthol and acetamide was considered as a representative example and conducted in the presence of a range of different catalysts (Table 4). Although comparative yields of the desired product were obtained in all cases, with the exception of the $\mathrm{P}(4 \mathrm{VPBSA}) \mathrm{HSO}_{4}$-catalyzed and sulfamic acid-catalyzed procedures, all of the other reported procedures required long reaction time, or high loadings of the catalyst (Table 4, Entry 5). These results clearly demonstrate that the $\mathrm{P}(4 \mathrm{VPBSA}) \mathrm{HSO}_{4}$ catalyst is equal to and in many cases much more efficient for this reaction than the other catalysts.

The performance of the current catalyst was also compared 


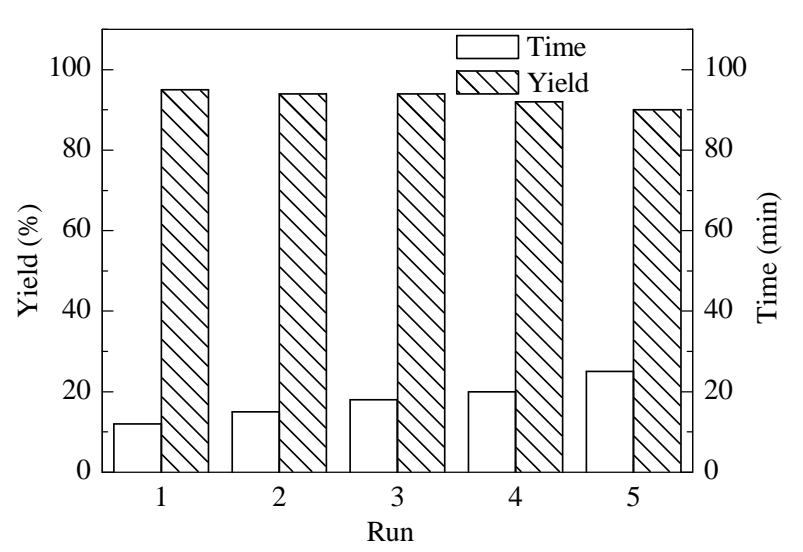

Fig. 4. Reusability of the catalyst in the reaction of benzaldehyde $(1.0$ $\mathrm{mmol})$ with $\beta$-naphthol $(1.0 \mathrm{mmol})$ and acetamide $(1.2 \mathrm{mmol})$ at $110^{\circ} \mathrm{C}$ under solvent-free conditions.

with a range of other reported catalysts for the preparation of substituted quinolines, as shown in Table 5. The results of this comparison study revealed that $\mathrm{P}(4 \mathrm{VPBSA}) \mathrm{HSO}_{4}$ accelerated the rate of the reaction considerably at the same time as providing a high yield of the desired product.

\section{Conclusions}

We have developed a facile and environmentally friendly protocol for the syntheses of 1-amidoalkyl-2-naphthols and substituted quinolines in the presence of poly(4-vinylpyridine butane sulfonic acid) as a novel environmentally safe heterogeneous solid acid catalyst under solvent-free conditions. This method offers several advantages over the existing catalytic systems including high yields, recyclable catalyst, short reaction time, facile work-up, and the ability to perform the reaction under solvent-free conditions.

\section{References}

[1] Mecerreyes D. Prog Polym Sci, 2011, 36: 1629

[2] Yuan J Y, Antonietti M. Polymer, 2011, 52: 1469
[3] Tanaka K, Toda F. Chem Rev, 2000, 100: 1025

[4] Davoodnia A, Zare-Bidaki A, Behmadi H. Chin J Catal (催化学报), 2012, 33: 1797

[5] Sayyafi M, Seyyedhamzeh M, Khavasi H R, Bazgir A. Tetrahedron, 2008, 64: 2375

[6] Singh M S, Chowdhury S. RSC Adv, 2012, 2: 4547

[7] Kusakabe Y, Nagatsu J, Shibuya M, Kawaguchi O, Hirose C, Shirato S. J Antibiot, 1972, 25: 44

[8] Remillard S, Rebhun L I, Howie G A, Kupchan S M. Science, 1975, 189: 1002

[9] Ren H, Grady S, Gamenara D, Heinzen H, Moyna P, Croft S L, Kendrick H, Yardley V, Moyna G. Bioorg Med Chem Lett, 2001, 11: 1851

[10] Benedini F, Bertolini G, Cereda R, Dona G, Gromo G, Levi S, Mizrahi J, Sala A.J Med Chem, 1995, 38: 130

[11] Clark R D, Caroon J M, Kluge A F, Repke D B, Roszkowski A P, Strosberg A M, Baker S, Bitter S M, Okada M D. J Med Chem, 1983, 26: 657

[12] Shen A Y, Tsai C T, Chen C L. Eur J Med Chem, 1999, 34: 877

[13] Ravindran A, Srivastava R. Chin J Catal (催化学报), 2011, 32: 1597

[14] Kantevari S, Vuppalapati S V N, Nagarapu L. Catal Commun, 2007, 8: 1857

[15] Das B, Laxminarayana K, Ravikanth B, Rao B R. J Mol Catal A, 2007, 261: 180

[16] Shaterian H R, Yarahmadi H, Ghashang M. Bioorg Med Chem Lett, 2008, 18: 788

[17] Nagarapu L, Baseeruddin M, Apuri S, Kantevari S. Catal Commun, 2007, 8: 1729

[18] Patil S B, Singh P R, Surpur M P, Samant S D. Ultrason Sonochem, 2007, 14: 515

[19] Lei M, Ma L, Hu L H. Tetrahedron Lett, 2009, 50: 6393

[20] Marco-Contelles J, Perez-Mayoral E, Samadi A, do Carmo Carreiras M, Soriano E. Chem Rev, 2009, 109: 2652

[21] Friedländer P. Ber Deutsch Chem Ges, 1882, 15: 2572

[22] Fehnel E A. J Org Chem, 1966, 31: 2899

[23] Yadav J S, Rao P P, Sreenu D, Rao R S, Kumar V N, Nagaiah K, Prasad A R. Tetrahedron Lett, 2005, 46: 7249

[24] Wang G W, Jia C S, Dong Y W. Tetrahedron Lett, 2006, 47: 1059

[25] Narasimhulu M, Srikanth Reddy T, Chinni Mahesh K, Prabhakar P, Bhujanga Rao C, Venkateswarlu Y. J Mol Catal A, 2007, 266: 114

[26] Dabiri M, Baghbanzadeh M, Nikcheh M S. Monatsh Chem, 2007, 138: 1249

\section{Table 4}

Comparison of $\mathrm{P}(4 \mathrm{VPBSA}) \mathrm{HSO}_{4}$ with other reported catalysts in the reaction of benzaldehyde with $\beta$-naphthol and acetamide.

\begin{tabular}{|c|c|c|c|c|c|}
\hline Entry & Catalyst/Condition & Catalyst loading (mol\%) & Time (min) & Yield (\%) & Ref. \\
\hline 1 & Montmorillonite $\mathrm{K} 10 /$ neat $125^{\circ} \mathrm{C}$ & $0.1 \mathrm{~g}$ & 90 & 89 & [14] \\
\hline 2 & $\mathrm{I}_{2}$ /Solvent-free $125^{\circ} \mathrm{C}$ & 5 & 330 & 85 & [15] \\
\hline 3 & $\mathrm{Fe}\left(\mathrm{HSO}_{4}\right)_{3} /$ Solvent-free $85^{\circ} \mathrm{C}$ & 5 & 65 & 83 & {$[16]$} \\
\hline 4 & $\mathrm{~K}_{5} \mathrm{CoW}_{12} \mathrm{O}_{40} \cdot 3 \mathrm{H}_{2} \mathrm{O} / 125^{\circ} \mathrm{C}$ & 1 & 120 & 90 & [17] \\
\hline 5 & Sulfamic acid/Ultrasound r.t. & 50 & 15 & 89 & [18] \\
\hline 6 & Thiamine $\mathrm{HCl} / \mathrm{EtOH}$ reflux & 10 & 240 & 90 & [19] \\
\hline 7 & $\mathrm{P}(4 \mathrm{VPBSA}) \mathrm{HSO}_{4} /$ Solvent-free $110^{\circ} \mathrm{C}$ & 10 & 12 & 95 & this work \\
\hline
\end{tabular}

Table 5

Comparison of $\mathrm{P}(4 \mathrm{VPBSA}) \mathrm{HSO}_{4}$ with several other reported catalysts for the reaction of 2-aminobenzophenone with acetyl acetone.

\begin{tabular}{lccccc}
\hline Entry & Catalyst/Temperature $\left({ }^{\circ} \mathrm{C}\right)$ & Catalyst loading (mol\%) & Time & Yield (\%) & Ref. \\
\hline 1 & $\mathrm{NaAuCl}_{4} \cdot 2 \mathrm{H}_{2} \mathrm{O} / 80$ & 3 & $1 \mathrm{~d}$ & {$[32]$} \\
2 & {$[\mathrm{Hbim}] \mathrm{BF}_{4} / 100$} & 100 & $3.3 \mathrm{~h}$ & 94 & {$[31]$} \\
3 & Oxalic acid $/ 80$ & 10 & $2 \mathrm{~h}$ & 90 & {$[26]$} \\
4 & $\mathrm{HClO}_{4}-\mathrm{SiO}_{2} / 60$ & $0.2 \mathrm{~g}$ & $2.5 \mathrm{~h}$ & 92 & {$[25]$} \\
5 & $\mathrm{P}(4 \mathrm{VPBSA}) \mathrm{HSO}_{4} / \mathrm{Solvent}^{-f r e e} / 110$ & 10 & $45 \mathrm{~min}$ & 88 & this work \\
\hline
\end{tabular}




\section{Graphical Abstract}

Chin. J. Catal., 2013, 34: 1861-1868 doi: 10.1016/S1872-2067(12)60659-7

Poly(4-vinylpyridinium butane sulfonic acid) hydrogen sulfate: An efficient, heterogeneous poly(ionic liquid), solid acid catalyst for the one-pot preparation of 1-amidoalkyl-2-naphthols and substituted quinolines under solvent-free conditions

Ali Reza Kiasat*, Arash Mouradzadegun, Seyyed Jafar Saghanezhad Shahid Chamran University, Iran

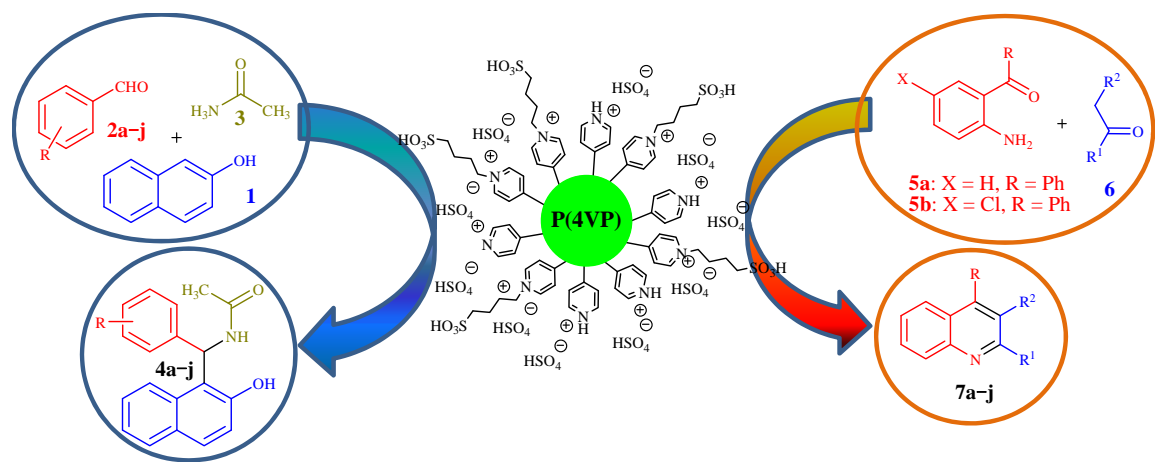

The application of poly(ionic liquids) (PILs) as novel catalysts provides chemists with the advantages of ionic liquids (ILs) as well as those of heterogeneous catalysts. Poly(4-vinylpyridinium butane sulfonic acid) hydrogen sulfate has been used as dual acidic PIL for the one-pot multi-component syntheses of 1-amidoalkyl-2-naphthols and substituted quinolones.

[27] Ghassamipour S, Sardarian A R. Tetrahedron Lett, 2009, 50: 514

[28] Barbero M, Bazzi S, Cadamuro S, Dughera S. Tetrahedron Lett, 2010, 51: 2342

[29] Zolfigol M A, Salehi P, Ghaderi A, Shiri M. Catal Commun, 2007, 8: 1214

[30] Genovese S, Epifano F, Marcotullio M C, Pelucchini C, Curini M. Tetrahedron Lett, 2011, 52: 3474

[31] Palimkar S S, Siddiqui S A, Daniel T, Lahoti R J, Srinivasan K V.J Org Chem, 2003, 68: 9371

[32] Atechian S, Nock N, Norcross R D, Ratni H, Thomas A W, Verron J, Masciadri R. Tetrahedron, 2007, 63: 2811

[33] Das B, Damodar K, Chowdhury N, Kumar R A. J Mol Catal A, 2007,

\section{4: 148}

[34] Kiasat A R, Mouradzadegun A, Saghanezhad S J. J Serb Chem Soc, 2013, 78: 469

[35] Kiasat A R, Mouradzadegun A, Saghanezhad S J. J Serb Chem Soc, 2013, doi: 10.2298/JSC121108008K. Ref. No. 5503

[36] Kiasat A R, Mouradzadegun A, Saghanezhad S J. Res Chem Intermed, doi: 10.1007/s11164-013-1194-0

[37] Mahdavinia G H, Bigdeli M A, Heravi M M. Chin Chem Lett, 2008, 19: 1171

[38] Kotadia D A, Soni S S. J Mol Catal A, 2012, 353-354: 44

[39] Ghorbani-Vaghei R, Akbari-Dadamahaleh S. Tetrahedron Lett, 2009, 50: 1055 